\title{
Equivalent Lung Dose and Systemic Exposure of Budesonide/Formoterol Combination via Easyhaler and Turbuhaler
}

\author{
Satu Lähelmä, MSc(Pharm),, Ulla Sairanen, MSc(Nutr), Jussi Haikarainen, MSc(Tech), \\ Jani Korhonen, MSc(Chem), Mikko Vahteristo, MSc(Stat), \\ Rainard Fuhr, $\mathrm{MD}, \mathrm{PhD}^{2}$, and Merja Kirjavainen, $\mathrm{PhD}^{1}$
}

\begin{abstract}
Background: Easyhaler ${ }^{\circledR}$ device-metered dry powder inhaler containing budesonide and formoterol fumarate dihydrate (hereafter formoterol) for the treatment of asthma and chronic obstructive pulmonary disease has been developed. The current approvals of the product in Europe were based on several pharmacokinetic (PK) bioequivalence (BE) studies, and in vitro-in vivo correlation (IVIVC) modeling.

Methods: Four PK studies were performed to compare the lung deposition and total systemic exposure of budesonide and formoterol after administration of budesonide/formoterol Easyhaler and the reference product, Symbicort Turbuhaler. The products were administered concomitantly with oral charcoal (lung deposition) and in two of the studies also without charcoal (total systemic exposure). Demonstration of BE for lung deposition (surrogate marker for efficacy) and non-inferiority for systemic exposure (surrogate marker for safety) were considered a proof of therapeutic equivalence. In addition, IVIVC models were constructed to predict study outcomes with different reference product fine particle doses (FPDs).

Results: In the first pivotal study, the exposure and lung dose via Easyhaler were higher compared to the reference product (mean comparison estimates between 1.07 and 1.28) as the FPDs of the reference product batch were low. In the following studies, reference product batches with higher FPDs were utilized. In the second pivotal study, non-inferiority of Easyhaler compared to Turbuhaler was shown in safety and BE in efficacy for all other parameters except the formoterol $\mathrm{AUC}_{\mathrm{t}}$. In the fourth study where two reference batches were compared to each other and Easyhaler, budesonide/formoterol Easyhaler was bioequivalent with one reference batch but not with the other having the highest FPDs amongst the 28 reference batches studied. In the IVIVC based study outcome predictions, the test product was bioequivalent with great proportion of the reference batches. For the test product and the median FPD reference product BE was predicted.

Conclusions: Equivalence regarding both safety and efficacy between budesonide/formoterol Easyhaler and Symbicort Turbuhaler was shown based on totality of evidence from the PK studies and IVIVC analyses, and therefore, therapeutic equivalence between the products can be concluded. The results of the PK studies are likely dependent on the variability of FPDs of the reference product batches.
\end{abstract}

Key words: budesonide, dry powder inhaler, Easyhaler, formoterol, lung deposition, pharmacokinetics, therapeutic equivalence, Turbuhaler

\footnotetext{
${ }^{1}$ Orion Corporation Orion Pharma, Espoo, Finland.

${ }^{2}$ PAREXEL Early Phase Clinical Unit, Berlin, Germany.

(C) S. Lahelma, U. Sairanen, J. Haikarainen, J. Korhonen, M. Vahteristo, R. Fuhr, and M. Kirjavainen. 2015; Published by Mary Ann Liebert, Inc. This Open Access article is distributed under the terms of the Creative Commons License (http://creativecommons.org/licenses/by/4.0), which permits unrestricted use, distribution, and reproduction in any medium, provided the original work is properly credited.
} 


\section{Introduction}

A STHMA AND CHRONIC OBSTRUCTIVE PULMONARY disease (COPD) represent inflammatory airway diseases that cause significant health problems to patients and a substantial economic burden on societies. ${ }^{(1,2)}$

During the last decades, inhaled corticosteroids (ICS) have been the first-line treatment for patients with persistent asthma irrespective of disease severity. ${ }^{(1,3,4)}$ Based on treatment guidelines, patients with asthma not sufficiently well controlled with ICS alone (plus a rapid-acting bronchodilator used as needed) should have a long-acting $\beta_{2}$ agonist (LABA) added. ${ }^{(1)}$ This combination therapy has an obvious scientific rationale as LABA and ICS may optimize each other's beneficial actions in the airways. ${ }^{(5)}$ Combining these two medications in one inhaler may simplify the dosing regimen and improve adherence to prescribed therapies for patients for whom combination therapy is appropriate. ${ }^{(6,7)}$ Fixed combination inhalers (dry powder inhalers, DPIs, and pressurized metered dose inhalers, pMDIs) containing both an ICS and a LABA (e.g., budesonide/ formoterol fumarate dihydrate (hereafter formoterol), fluticasone propionate/salmeterol, or fluticasone propionate/ formoterol) currently have an established position among the treatment options of asthma.

The originator budesonide/formoterol combination, Symbicort $^{\circledR}$ Turbuhaler (AstraZeneca, London, United Kingdom) was initially used only as maintenance treatment with one or two administrations daily, but an adjustable maintenance therapy was subsequently developed. ${ }^{(8,9)}$ Later, a posology was accepted by regulatory authorities with maintenance therapy plus additional doses as needed (called SMART; Symbicort Maintenance And Reliever Therapy). ${ }^{(10)}$ Several asthma studies have shown the clinical advantage of the budesonide/formoterol SMART therapy. ${ }^{(11)}$ The safety profile of budesonide/formoterol has also been thoroughly documented. ${ }^{(12)}$ The use of a combination inhaler incorporating both ICS and LABA in patients with asthma ensures that, as stated in the GINA guideline, the LABA is not administered alone. ${ }^{(1)}$ In patients with COPD the ICS/LABA combinations have been shown to improve airway function, reduce symptoms, improve quality of life, prevent exacerbations, and prolong the time to the next exacerbation. ${ }^{(13,14)}$ Comprehensive reviews of the use of the budesonide/formoterol in patients with COPD have also been published. ${ }^{(15,16)}$

Orion Pharma (Espoo, Finland) has developed a budesonide/formoterol combination to be delivered via the Easyhaler $^{\circledR}$, a device-metered DPI. The mono-components of the product, budesonide and formoterol, as well as sal- butamol and beclometasone, are available on the market in the Easyhaler inhaler. Addition of the ICS/LABA combination to the Easyhaler product portfolio was considered important because patients may benefit from use of only one type of inhaler for their medication. ${ }^{(17)}$ In the development of the product, the European Medicine Agency (EMA) guideline on the requirements for clinical documentation for orally inhaled products (OIPs) ${ }^{(18)}$ has been followed. According to the guideline, a second entry orally inhaled combination product has to demonstrate therapeutic equivalence with the reference combination product for both active substances of the test combination product. In case therapeutic equivalence cannot be proven based on in vitro data, pharmacokinetic (PK) and clinical studies are required. We report here the results of four PK studies that evaluated whether equivalent pulmonary deposition (lung dose after blocking of the gastro-intestinal, GI, uptake with charcoal) and systemic exposure (without charcoal blockage) were demonstrable after inhalation of budesonide/formoterol via Easyhaler and Turbuhaler.

\section{Materials and Methods}

\section{Study drugs}

Symbicort Turbuhaler Forte $(320 \mu \mathrm{g}$ budesonide/ $9 \mu \mathrm{g}$ formoterol per inhalation) as the reference product (hereafter Symbicort Turbuhaler) and budesonide/formoterol Easyhaler 320/9 $\mu \mathrm{g}$ per inhalation were the investigational medicinal products in all four studies. In addition, respective placebos were needed in double-blind studies (doubledummy approach), and for charcoal block Carbomix granules (Leiras Takeda, Helsinki, Finland) were utilized.

\section{Study subjects}

Healthy male and female subjects aged 18-60 years with a body mass index (BMI) $>19$ and $<30 \mathrm{~kg} / \mathrm{m}^{2}$, weight at least $50 \mathrm{~kg}$, a forced expiratory volume in one second $\left(\mathrm{FEV}_{1}\right) \geq 80 \%$ of predicted normal, and good general health were recruited for the studies. Smokers of more than five cigarettes per day were excluded, as were pregnant or breast-feeding females and those of childbearing potential not using adequate contraception.

\section{Methods}

This report consists of four PK studies on inhaled budesonide/formoterol administered by Easyhaler and Turbuhaler. The flow of the studies is shown in Figure 1. The pilot and the first pivotal study were performed in parallel, and after them the second pivotal study and the fourth study,

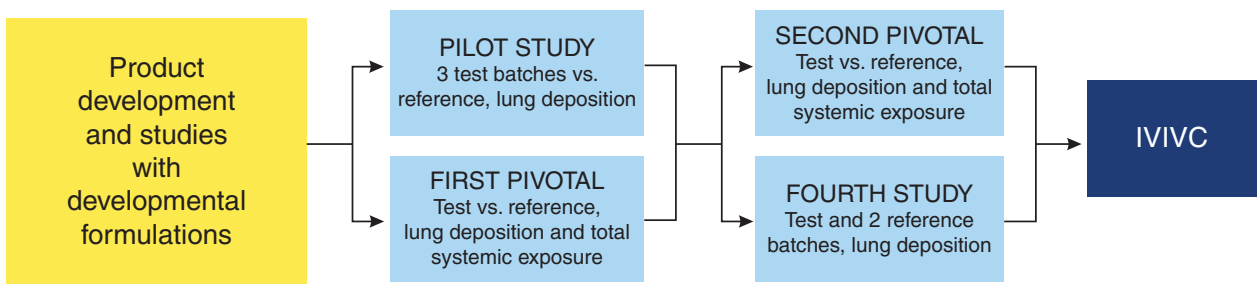

FIG. 1. Flow chart of budesonide/formoterol Easyhaler pharmacokinetic studies. IVIVC, In vitro-in vivo correlation. 
also in parallel. In the pilot study, lung deposition of budesonide and formoterol was assessed and compared after administration of three different batches of budesonide/ formoterol Easyhaler, and one Symbicort Turbuhaler batch. The aim of the pivotal studies was to demonstrate both BE in terms of lung deposition and non-inferiority in terms of systemic exposure between the products. The primary aim of the fourth study was to evaluate the acceptance range with which two Symbicort Turbuhaler batches (A and B) could be declared bioequivalent (BE). The secondary objective of the study was to compare PK parameters of budesonide/formoterol Easyhaler with the Turbuhaler batches.

In all studies the same budesonide/formoterol Easyhaler batch was included (in the pilot also two additional Easyhaler batches). For the reference product four different batches were utilized. The same reference product batch was used in the first two studies. In the second pivotal study one and in the fourth study two new reference product batches were introduced.

Reference product fine particle doses (FPDs, the mass of particles under $5 \mu \mathrm{m}$ ) were studied throughout the budesonide/formoterol Easyhaler development program with increasing number of batches over time. Altogether six batches had been purchased and analyzed before the start of the first two studies, whereas the number of batches was 24 before the start of the last two studies. Four additional batches were purchased during the registration process of the product, resulting altogether in 28 reference product batches in the database. FPDs were determined according to the in vitro testing of DPIs established by the European Pharmacopoeia monograph Preparations for Inhalation ${ }^{(19)}$ using Next Generation Impactor (NGI, apparatus E). The number of inhalers analyzed was typically between three to five for both Easyhaler and Turbuhaler. The in vitro studies were performed by Oy Medfiles Ltd, Kuopio, Finland.

The PK studies were performed according to a 3 or 4period, 3 or 4-treatment, crossover design. The pilot study was an open study, but all others were carried out as doubleblind with double-dummy technique. Study treatments, a single dose consisting of two inhalations of the budesonide/ formoterol 320/9 $\mu \mathrm{g}$ per inhalation via Easyhaler or Turbuhaler (total dose 640/18 $\mu \mathrm{g}$ ), were administered in a randomized order concomitantly with charcoal in all studies and in the pivotal studies also without charcoal.

The charcoal regimen used to block the GI absorption was as follows: immediately before study treatment administration, the mouth was thoroughly rinsed with $50 \mathrm{~mL}$ of charcoal suspension before swallowing. The charcoal administration was repeated immediately after study treatment and again when $45 \mathrm{~min}$ and $1 \mathrm{~h} 30 \mathrm{~min}$ had elapsed. The efficiency of the block was confirmed in a separate PK study in healthy volunteers. A single oral dose of $640 / 18 \mu \mathrm{g}$ of budesonide/ formoterol was administered with and without the charcoal and the blockage of GI absorption was found to be $98.8 \%$ for budesonide and $99.8 \%$ for formoterol (data on file).

In all studies the subjects were trained in the correct use of the inhalers at the screening visit and before each study drug administration. The studies consisted of a screening period, three or four treatment days separated by at least 3day wash-out periods, and an end-of-study visit occurring at least 3 days after the last study treatment administration. Blood samples for the determination of budesonide and formoterol concentrations in plasma were drawn before the administration of the study treatments and up to $12 \mathrm{~h}$ for budesonide and up to $24 \mathrm{~h}$ for formoterol after drug administration. The sampling time points (hours:minutes) after the administration of the study drugs were: 0:05, 0:07, 0:10, $0: 15,0: 20,0: 30,0: 45,1: 00,1: 30,2: 30,4: 00,6: 00,8: 00$, and 12:00 for both drugs, and in addition 24:00 for formoterol analysis only. Budesonide and formoterol concentrations in plasma were determined by separate, validated liquid chromatography-tandem mass spectrometry (LC-MS/MS) methods at PPD, Madison, WI, USA. The lower limit of quantification (LLOQ) for the budesonide method $\mathrm{P} 4290.01^{(20)}$ was $10 \mathrm{pg} / \mathrm{mL}$ and for the formoterol method P860.02 2 (21) $0.5 \mathrm{pg} / \mathrm{mL}$. The bioanalytical analyses were performed according to the principles of applicable good laboratory practice (GLP) and good clinical practice (GCP).

As primary markers of efficacy, the following variables were calculated from concentration-time curves for budesonide and formoterol after study drug administration with charcoal: the maximum observed concentration of concentration-time curve $\left(\mathrm{C}_{\max }\right)$ and the area under the concentration-time curve from time zero to the last sample with quantifiable drug concentration $\left(\mathrm{AUC}_{\mathrm{t}}\right)$ calculated with the linear trapezoidal rule. The secondary $\mathrm{PK}$ parameters were the area under the concentration-time curve from time zero to infinity $\left(\mathrm{AUC}_{\infty}\right)$ determined by adding $\mathrm{AUC}_{\mathrm{t}}$ to the extrapolated area that was determined dividing the last quantifiable concentration by $\lambda_{\mathrm{z}}\left(\lambda_{\mathrm{z}}=\right.$ the terminal elimination rate constant from log-linear portion of a concentration-time curve), the time to reach the maximum concentration $\left(t_{\max }\right)$, and the terminal elimination half-life $\left(t_{1 / 2}\right)$ calculated with the equation $\ln 2 / \lambda_{\mathrm{z}}$. As surrogate markers for safety, the same PK variables as above were calculated after administration of the test and the reference products without GI charcoal block. The PK parameters were calculated by a noncompartmental method using the WinNonlin ${ }^{\circledR}$ 5.0.1 (Certara L.P, St. Louis, MO, USA) computer program. The actual time of sampling was used in the calculations. The zero time was the start of the first inhalation of the active study treatment.

Clinical safety was assessed by supine heart rate (HR), systolic and diastolic blood pressure (BP), 12-lead electrocardiogram (ECG), physical examination, laboratory safety assessments, and adverse events (AEs). The pilot and the fourth study were performed at PAREXEL Early Phase Clinical Unit, Berlin, Germany, and the pivotal studies at Orion Pharma Clinical Pharmacology Unit, Espoo, Finland. All four studies were performed according to GCP and the Declaration of Helsinki. The study protocols were approved by the national regulatory authorities and ethics committees before the start of the study procedures. All subjects gave their written informed consent to participate in the studies.

\section{Statistical methods}

The determination of sample size for individual studies was based on previous studies with the developmental formulations of budesonide/formoterol Easyhaler product. The mean squared error (MSE) of budesonide $\mathrm{C}_{\max }$ was the highest of the primary parameters and was therefore used in the sample size calculations. It was assumed that the 
expected ratio of means would be 0.9-1.1. The per protocol (PP) data set was used when comparing the PK results. The PP data set excluded all the subjects who discontinued, had a major protocol deviation, or insufficient number of PK samples for the calculation of reliable PK parameters. The primary $\mathrm{PK}$ variables for lung deposition, $\mathrm{C}_{\max }$ and $\mathrm{AUC}_{\mathrm{t}}$, were analyzed using a general linear mixed model. The responses were modeled using logarithmic transformations. By taking exponential back-transformations, the results were returned to the original scale, yielding the ratio of geometric means and their $90 \%$ confidence intervals (CIs). These CIs were evaluated against the conventional BE region from 0.80 to 1.25 . The secondary $\mathrm{PK}$ variables were $\mathrm{AUC}_{\infty}, \mathrm{t}_{\max }$ and $\mathrm{t}_{1 / 2}$. AUC $\infty$ was analyzed in the same way as $\mathrm{C}_{\max }$ and $\mathrm{AUC}_{\mathrm{t}}$. The primary safety variables $\mathrm{C}_{\max }$ and $\mathrm{AUC}_{\mathrm{t}}$ (administration without charcoal) were analyzed and described as above for BE. Non-inferiority (i.e., not having higher exposure after test than after the reference product) for both budesonide and formoterol was evaluated. The upper limit of the one-sided $95 \%$ CI for the ratio of the geometric means of primary PK parameters was not to exceed 1.25 .

\section{In vitro-in vivo correlation (IVIVC)}

The lung deposition data obtained was further explored from an IVIVC perspective by constructing models to predict study outcomes with different reference product FPDs. The T/R-ratios of the primary parameters $\left(\mathrm{AUC}_{t}\right.$ and $\mathrm{C}_{\max }$ ) versus the T/R-ratios of FPDs of the batches under comparison were used. A linear regression was built separately for all primary PK parameter T/R-ratios to model them with the FPD ratios. The modeling was done based on altogether five comparisons between the Easyhaler batch and four reference batches (i.e., with all comparisons available after administration of the products concomitantly with charcoal). Validation of the predictability of the models was carried out as instructed in the regulatory guidance. ${ }^{(22,23)}$ All the reference batches with FPDs falling within the limits of $\pm 15 \%$ of the median FPD were used in the predictions $(n=26)$. A prediction for the comparison between budesonide/formoterol Easyhaler and the median FPD reference product batch was also carried out.

All statistical analyses were performed with $\mathrm{SAS}^{\circledR}$ for Windows (SAS Institute Inc., Cary, NC, USA).

\section{Results}

There is notable batch-to-batch variability in the FPDs of the reference product (Fig. 2). The mean FPDs of the batches utilized in the PK studies varied between 125 and $154 \mu \mathrm{g} /$ inhalation for budesonide and between 3.6 and $4.4 \mu \mathrm{g} /$ inhalation for formoterol. The median FPD was $138 \mu \mathrm{g} /$ inhalation for budesonide and $4.0 \mu \mathrm{g}$ /inhalation for formoterol.

There were no major differences in demographic and baseline characteristics of the subjects in the studies (Table 1).

In the first pivotal study, absorption of both budesonide and formoterol was slightly higher from budesonide/formoterol Easyhaler than from Symbicort Turbuhaler after administration with $(N=69)$ and without $(N=65)$ charcoal (Tables 2 and 3, Fig. 3). Three out of the eight primary parameters fulfilled the pre-specified BE/non-inferiority criteria, but for the rest of the parameters the results were inconclusive with CIs for the T/R-ratios overlapping the acceptance range. In regard to $\mathrm{T} / \mathrm{R}$ comparisons, the results of the pilot study $(N=16)$ were in line with the results of the first pivotal study. Differences in PK parameters between the different Easyhaler batches (A, B, and C) were small (Tables 2 and 3).

As the FPDs of the reference product studied in the first two studies were found to be relatively low (Fig. 2) two additional studies were carried out (Fig. 1). In the second pivotal study ( $N=69$ for lung deposition and $N=65$ for total systemic exposure comparisons) all except one of the eight primary parameters fulfilled the pre-specified $\mathrm{BE}$ and noninferiority criteria (Fig. 3). However, the CI of formoterol $\mathrm{AUC}_{\mathrm{t}}$ exceeded (but overlapped) the acceptance limit of 0.80 (contrary to the first pivotal study in which the overlap was at the upper limit). In other words, the first pivotal study results showed higher absorption after inhalation via Easyhaler (comparison estimates $>1$ ), whereas in the second pivotal the estimates were closer to 1 and within the acceptance limits except for formoterol $\mathrm{AUC}_{\mathrm{t}}$. The shapes of the budesonide and formoterol plasma concentration mean curves were similar for both products, showing similar absorption and elimination profiles in general (Fig. 4).

The results of the fourth study, which utilized two Symbicort Turbuhaler batches (A and B), are shown in Figure 5. For the PK parameter comparisons $(N=47-48)$, BE between the two reference batches could not be demonstrated. The comparison of budesonide/formoterol Easyhaler with Symbicort Turbuhaler batch A showed BE with geometric means and $90 \%$ CIs between 0.8 and 1.25. However, when comparing budesonide/formoterol Easyhaler with Symbicort Turbuhaler batch B BE was not shown as a reflection of high FPDs of Turbuhaler batch B.

The secondary parameters $t_{\max }$ and $t_{1 / 2}$ were comparable between the test and the reference products in all studies. The median budesonide $t_{\max }$ varied from 10 to 20 minutes and median formoterol $t_{\max }$ from 5 to 8 minutes in different studies irrespective of the product. Mean $t_{1 / 2}$ for budesonide varied from 3.1 to $3.6 \mathrm{~h}$ and mean $\mathrm{t}_{1 / 2}$ for formoterol from 8.5 to 12 hours. The obtained $\mathrm{AUC}_{\infty}$ values were in line with the corresponding $\mathrm{AUC}_{\mathrm{t}}$ values.

Based on the results there was a rank order correlation between FPDs of the reference product and the PK results obtained (i.e., when a reference product had low FPDs it resulted in high T/R-ratios of $\mathrm{PK}$ parameters and vice versa). Therefore, IVIVC models were constructed for the primary parameters. As an example of the IVIVC models, the model for budesonide $\mathrm{AUC}_{\mathrm{t}}$ and the respective predictions for different reference product batches are shown in Figure 6. Based on the results, the test product is bioequivalent with great proportion of the reference batches. The equation for the model is $\mathrm{y}=-0.22+1.36 \mathrm{x}$, where $\mathrm{y}$ is the T/R-ratio of budesonide $\mathrm{AUC}_{t}$ and $\mathrm{x}$ is T/R-ratio of budesonide FPD. The IVIVC models had high coefficients of determination (between 0.77 and 0.88), indicating that a large proportion of the variation in the T/R-ratio of $\mathrm{PK}$ parameters could be explained by the variation in the FPD of the reference product. In the validation of the predictability, all the average absolute percent prediction errors were $\leq 10 \%$ and all the individual absolute percent prediction errors were $\leq 15 \%$, suggesting a good predictive 

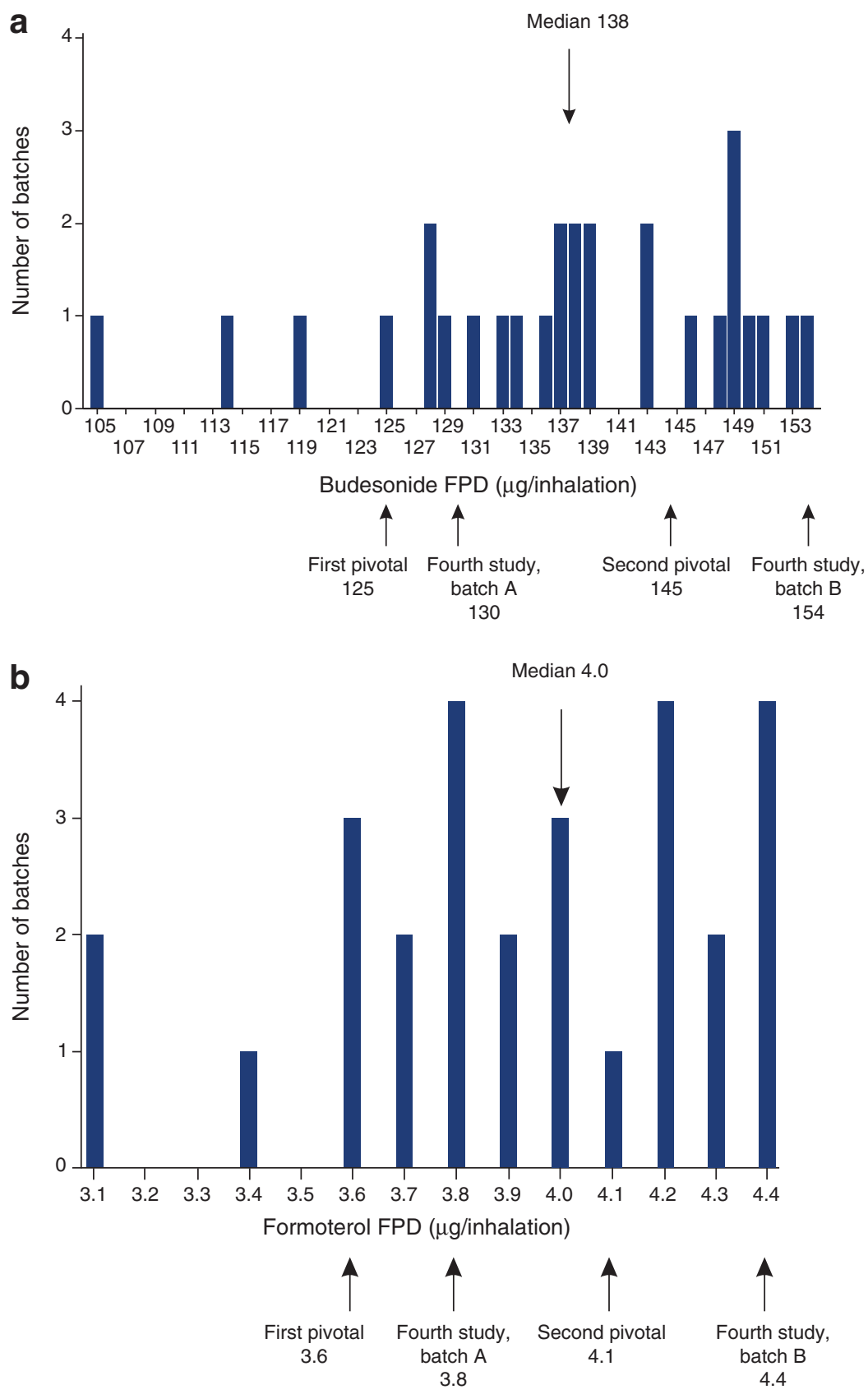

FIG. 2. Budesonide (a) and formoterol (b) fine particle doses (FPDs, $\mu \mathrm{g} /$ inhalation) of the tested reference product batches $(N=28)$.

Table 1. Demographic Data (ITT Population)

\begin{tabular}{lcccc}
\hline & Pilot study & First pivotal & Second pivotal & Fourth study \\
\hline No. of subjects & 17 & 74 & 72 & 48 \\
Females, \% & 47 & 50 & 53 & 48 \\
Mean age (range) years & $37(22-51)$ & $31(18-59)$ & $27(18-57)$ & $44(18-55)$ \\
Mean weight (range) kg & $74(51-95)$ & $71(50-111)$ & $70(52-105)$ & $77(57-103)$ \\
Mean height (range) cm $\mathrm{cm}$ & $173(154-188)$ & $174(156-198)$ & $174(159-197)$ & $174(156-188)$ \\
Mean BMI (range) $\mathrm{kg} / \mathrm{m}^{2}$ & $25(20-30)$ & $23(19-30)$ & $23(19-30)$ & $25(21-30)$ \\
Mean FEV $_{1}, \%$ of predicted (range) & $109(83-128)$ & $98(80-128)$ & $98(81-126)$ & $109(87-147)$
\end{tabular}


Table 2. Primary Pharmacokinetic Parameters of Budesonide After Single Dose of Two InHAlations of Budesonide/Formoterol EASYHALER 320/9 $\mu$ G/INHALATION and Symbicort Turbuhaler Forte (PP Population)

\begin{tabular}{|c|c|c|c|c|}
\hline & \multicolumn{2}{|c|}{ Budesonide $C_{\max }(\mathrm{pg} / \mathrm{mL})$} & \multicolumn{2}{|c|}{ Budesonide $A U C_{t}(h \times p g / m L)$} \\
\hline & $\begin{array}{c}\text { Mean } \\
(90 \% \text { CI) }\end{array}$ & $\begin{array}{c}\text { Intra-subject } \\
C V(\%)\end{array}$ & $\begin{array}{c}\text { Mean } \\
(90 \% \text { CI) }\end{array}$ & $\begin{array}{c}\text { Intra-subject } \\
C V(\%)\end{array}$ \\
\hline \multicolumn{5}{|l|}{ Pilot } \\
\hline B/F Easyhaler (batch A) & $2030(1744-2363)$ & 22 & $4494(4001-5048)$ & 17 \\
\hline B/F Easyhaler (batch B) & $1881(1616-2190)$ & & $4577(4075-5141)$ & \\
\hline B/F Easyhaler (batch C) & $1841(1582-2143)$ & & $4955(4411-5565)$ & \\
\hline Symbicort Turbuhaler & $1506(1294-1753)$ & & $3677(3274-4130)$ & \\
\hline \multicolumn{5}{|l|}{ First pivotal } \\
\hline $\mathrm{B} / \mathrm{F}$ Easyhaler & $1978(1832-2135)$ & 34 & $4867(4618-5129)$ & 20 \\
\hline Symbicort Turbuhaler & $1543(1430-1666)$ & & $3881(3683-4090)$ & \\
\hline $\mathrm{B} / \mathrm{F}$ Easyhaler without $\mathrm{CC}$ & $2138(1990-2298)$ & 30 & $5403(5144-5674)$ & 15 \\
\hline Symbicort Turbuhaler without CC & $1690(1572-1816)$ & & $4415(4204-4637)$ & \\
\hline \multicolumn{5}{|l|}{ Second pivotal } \\
\hline B/F Easyhaler & 1709 (1599-1826) & 28 & 4492 (4296-4697) & 17 \\
\hline Symbicort Turbuhaler & $1816(1699-1940)$ & & $4590(4389-4799)$ & \\
\hline $\mathrm{B} / \mathrm{F}$ Easyhaler without $\mathrm{CC}$ & $1966(1824-2119)$ & 28 & $5103(4845-5376)$ & 16 \\
\hline Symbicort Turbuhaler without CC & 1875 (1739-2021) & & $4937(4687-5200)$ & \\
\hline \multicolumn{5}{|l|}{ Fourth study } \\
\hline $\mathrm{B} / \mathrm{F}$ Easyhaler & $1823(1661-2001)$ & 28 & $4144(3878-4428)$ & 20 \\
\hline Symbicort Turbuhaler (batch A) & $1730(1576-1899)$ & & $3787(3544-4047)$ & \\
\hline Symbicort Turbuhaler (batch B) & $1996(1818-2190)$ & & $4242(3970-4533)$ & \\
\hline
\end{tabular}

B/F Easyhaler, budesonide/formoterol Easyhaler; CV\%, coefficient of variation; mean, estimated geometric mean; $90 \%$ CI, $90 \%$ confidence interval for the mean. Administration with concomitant charcoal except when separately mentioned (without CC).

Table 3. Primary Pharmacokinetic Parameters of Formoterol After Single Dose of Two Inhalations of Budesonide/Formoterol EASYHaler 320/9 $\mu \mathrm{G} /$ INHalation and Symbicort Turbuhaler Forte (PP Population)

\begin{tabular}{|c|c|c|c|c|}
\hline & \multicolumn{2}{|c|}{ Formoterol $C_{\max }(\mathrm{pg} / \mathrm{mL})$} & \multicolumn{2}{|c|}{ Formoterol AUC $(h \times p g / m L)$} \\
\hline & $\begin{array}{c}\text { Mean } \\
(90 \% \text { CI })\end{array}$ & $\begin{array}{c}\text { Intra-subject } \\
C V(\%)\end{array}$ & $\begin{array}{c}\text { Mean } \\
(90 \% \text { CI })\end{array}$ & $\begin{array}{c}\text { Intra-subject } \\
C V(\%)\end{array}$ \\
\hline \multicolumn{5}{|l|}{ Pilot } \\
\hline B/F Easyhaler (batch A) & $33(28-39)$ & 24 & $63(55-73)$ & 21 \\
\hline B/F Easyhaler (batch B) & $34(29-40)$ & & $71(62-82)$ & \\
\hline B/F Easyhaler (batch C) & $35(30-41)$ & & $71(61-81)$ & \\
\hline Symbicort Turbuhaler & $29(25-34)$ & & $64(55-74)$ & \\
\hline \multicolumn{5}{|l|}{ First pivotal } \\
\hline B/F Easyhaler & $40(37-43)$ & 26 & $86(81-91)$ & 23 \\
\hline Symbicort Turbuhaler & $32(30-34)$ & & $78(73-83)$ & \\
\hline $\mathrm{B} / \mathrm{F}$ Easyhaler without $\mathrm{CC}$ & $41(38-44)$ & 21 & $106(101-112)$ & 15 \\
\hline Symbicort Turbuhaler without CC & $35(32-37)$ & & $99(94-105)$ & \\
\hline \multicolumn{5}{|l|}{ Second pivotal } \\
\hline B/F Easyhaler & $33(31-35)$ & 23 & $74(71-78)$ & 19 \\
\hline Symbicort Turbuhaler & $38(36-40)$ & & $93(88-98)$ & \\
\hline $\mathrm{B} / \mathrm{F}$ Easyhaler without $\mathrm{CC}$ & $35(33-37)$ & 19 & $97(92-102)$ & 16 \\
\hline Symbicort Turbuhaler without CC & $38(36-40)$ & & $105(100-110)$ & \\
\hline \multicolumn{5}{|l|}{ Fourth study } \\
\hline B/F Easyhaler & $21(19-23)$ & 26 & $42(38-47)$ & 31 \\
\hline Symbicort Turbuhaler (batch A) & $23(21-26)$ & & $47(42-52)$ & \\
\hline Symbicort Turbuhaler (batch B) & $27(25-30)$ & & $59(53-66)$ & \\
\hline
\end{tabular}

B/F Easyhaler, budesonide/formoterol Easyhaler; CV\%, coefficient of variation; mean, estimated geometric mean; $90 \% \mathrm{CI}$, the $90 \%$ confidence interval for the mean. Administration with concomitant charcoal except when separately mentioned (without CC). 

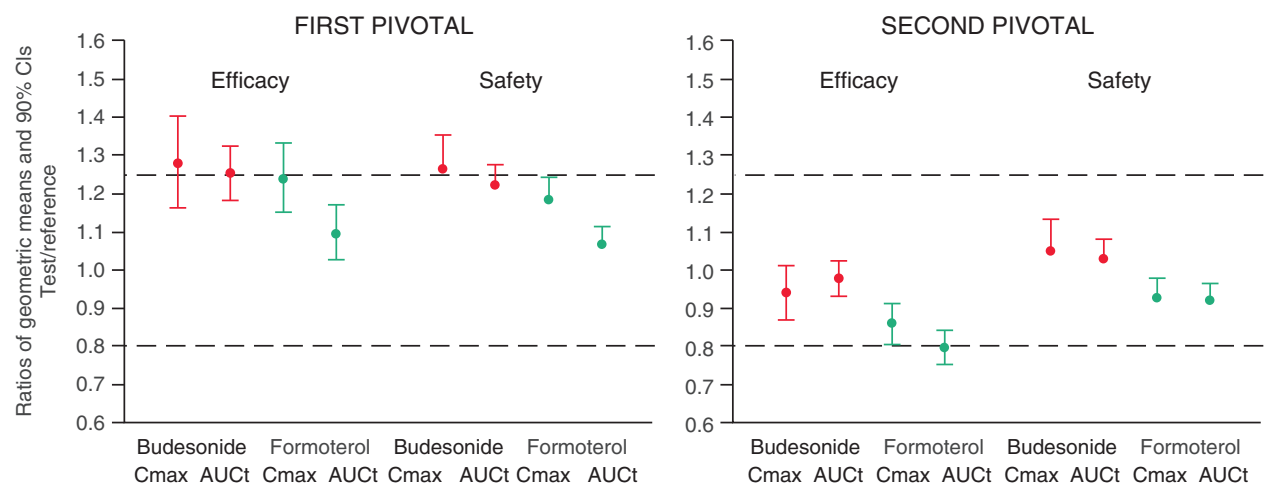

FIG. 3. Summary of budesonide and formoterol $\mathrm{C}_{\max }$ and $\mathrm{AUC}_{\mathrm{t}}$ comparisons between the test and the reference product in the pivotal studies (PP population). The bioequivalence/noninferiority limits are shown with dotted lines.

performance by the models. In addition to the predictions of the study outcomes with different reference batches, a prediction for the comparison between budesonide/formoterol Easyhaler and a reference product batch with median FPDs was carried out. The prediction shows bioequivalent lung deposition between the test and reference product (Fig. 7).

There were no safety issues in any of the studies and no serious AEs were reported. AE profiles were similar after both inhalers. Altogether 3 subjects discontinued due to an AE. One subject discontinued in the first pivotal study due to vasovagal syncope after Easyhaler administration, and one subject in the second pivotal study due to tremor of the whole body after Turbuhaler. Both events were assessed as related to the study treatment. In the pilot study, one subject discontinued due to vasovagal reaction (presyncope) due to blood sampling. The events resolved spontaneously.

\section{Discussion}

In support of efficacy and safety of budesonide/formoterol Easyhaler, PK studies were performed to compare the lung dose and total systemic exposure of budesonide and formoterol with the reference product. An open pilot study and three double-blind, randomized, crossover, single dose studies were carried out. In the pilot and the first pivotal studies, the exposure and lung dose of budesonide and formoterol via Easyhaler were higher compared to the reference product. In these studies the FPDs of the reference product batch were fairly low. In the following pivotal and the fourth study, different reference product batches with higher FPDs were utilized. In the second pivotal study, non-inferiority of Easyhaler compared to Turbuhaler was shown in safety and equivalence in efficacy was demonstrated for all other parameters except the formoterol $\mathrm{AUC}_{\mathrm{t}}$. In the fourth study budesonide/formoterol Easyhaler was bioequivalent with one Symbicort Turbuhaler batch but not with the other, having the highest FPDs amongst the 28 batches studied.

Because budesonide/formoterol Easyhaler batch was the same in all studies, the study results suggest that a reference product with high FPDs results in lower test/reference-ratios of the PK parameters and a reference product with low FPDs results in higher ratios. To further evaluate the relationship between the PK parameters and in vitro measured FPDs, IVIVC models were constructed. The predicted study outcome results covered the $\mathrm{BE}$ acceptance range (0.80-1.25) from the low to the high end even when the reference product FPDs were within $\pm 15 \%$ of the median. For the test product and the median FPD reference product bioequivalent lung dose was predicted.

The EMA guideline on the requirements for clinical documentation for OIPs has been followed in the development of budesonide/formoterol Easyhaler to the extent possible and necessary. The guideline provides a stepwise approach to demonstrate therapeutic equivalence between inhaled products, the originator, and a second entry product. The first step involves in vitro comparisons between the test and reference products. In some cases, the use of only comparative in vitro data may be considered acceptable if the product satisfies all the criteria set out in the guideline. In vitro comparisons did not show complete equivalence between budesonide/formoterol Easyhaler and Symbicort Turbuhaler. This is typical for DPIs not resembling the originator in design. Hence, PK studies (second step) in healthy volunteers were performed. The data from the studies together with the required in vitro investigations form the basis of budesonide/formoterol Easyhaler marketing authorizations in Europe. ${ }^{(24)}$

The guideline calls for the use of intended patient population in PK trials with OIPs. ${ }^{(18)}$ The use of healthy volunteers deviates from this principle but is currently accepted by the regulatory authorities as healthy volunteers are considered less variable and more discriminative than patients with asthma. ${ }^{(25)}$ The findings of studies in healthy volunteers can be bridged to patients when the flow rate dependency characteristics of the products can be considered similar. Budesonide/formoterol Easyhaler and Symbicort Turbuhaler display similar patterns of flow rate dependency within clinically relevant flow limits in asthma and COPD patients. ${ }^{(26)}$

As an option to PK studies, lung dose of an inhaled drug can be assessed by using an imaging study. ${ }^{(18)}$ Imaging studies might give a better estimate especially on regional quantification of the pulmonary deposition compared to PK studies but there are challenges related to their performance (e.g., validation of radiolabeling of drug formulation, short half-life of some radionuclides) and standardization of methodology. ${ }^{(27)}$ At present, the European authorities consider plasma concentrations obtained in a PK study to be indicative of the concentrations at the site of action, ${ }^{(28)}$ and 

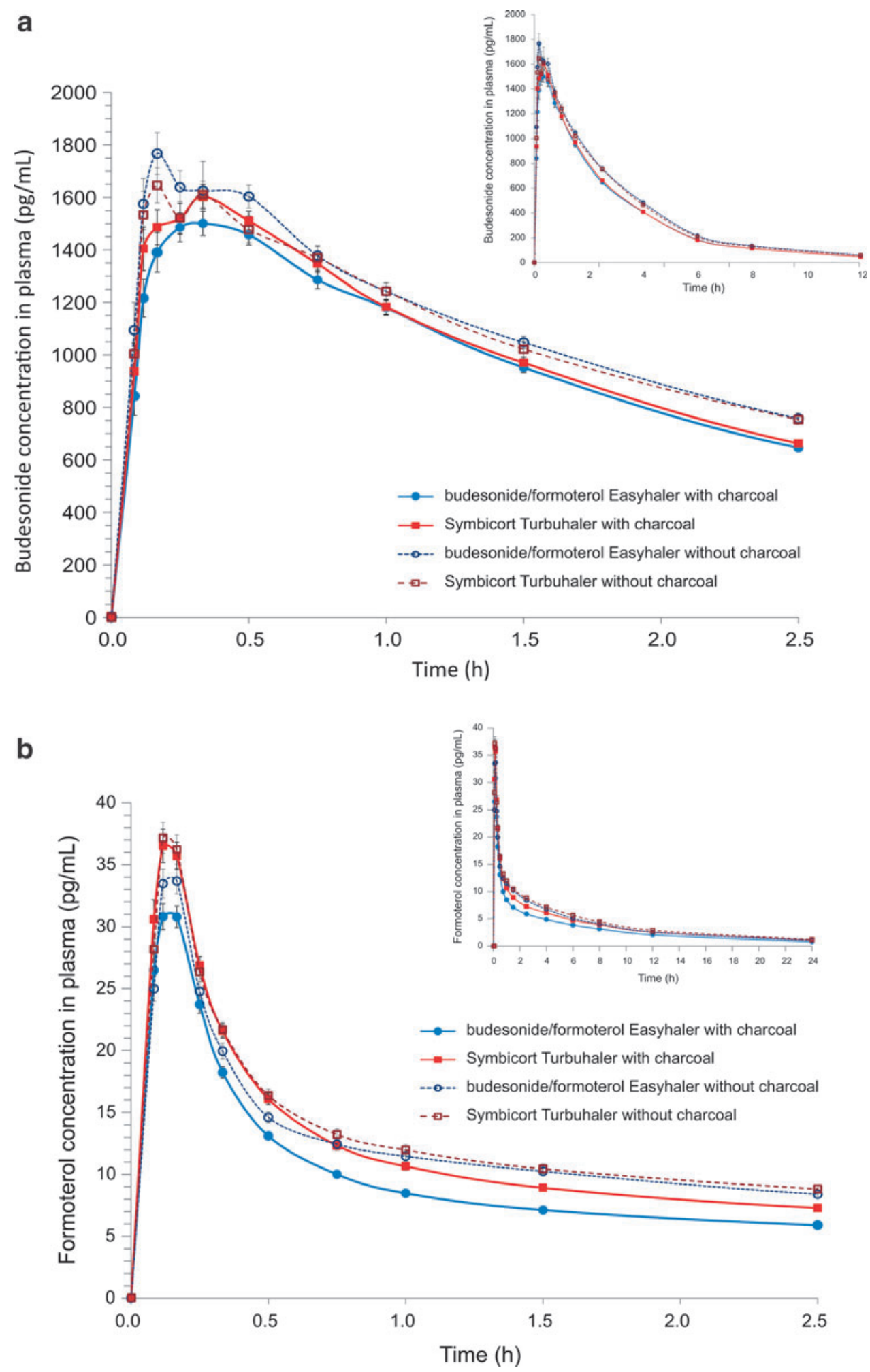

FIG. 4. Budesonide (a) and formoterol (b) concentrations in plasma (pg/mL) after two inhalations of budesonide/formoterol Easyhaler 320/9 $\mu \mathrm{g} / \mathrm{inh}$ alation and Symbicort Turbuhaler Forte with and without concomitant charcoal administration in the second pivotal study (PP population, mean \pm SE). 

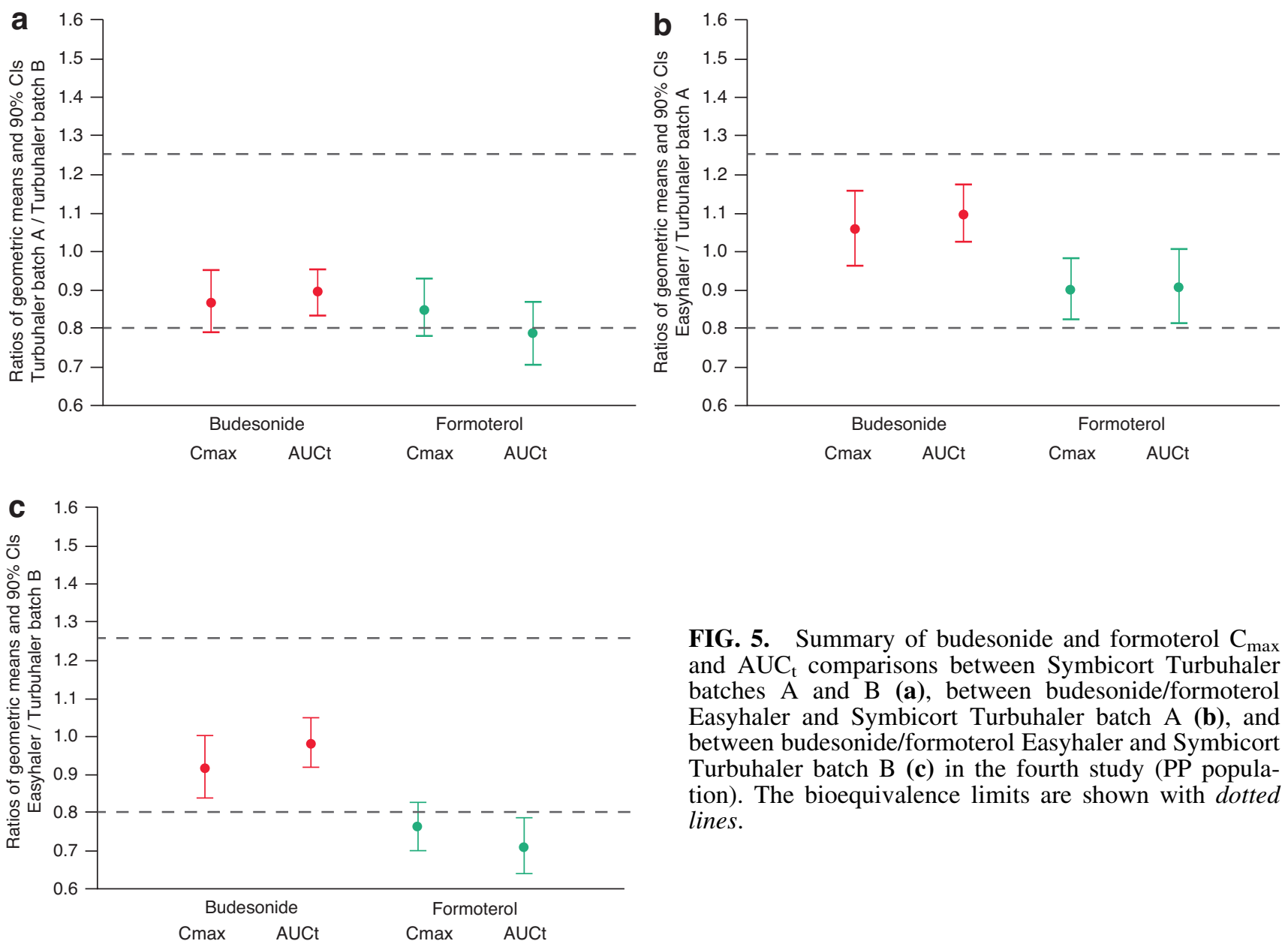

FIG. 5. Summary of budesonide and formoterol $\mathrm{C}_{\max }$ and $\mathrm{AUC}_{\mathrm{t}}$ comparisons between Symbicort Turbuhaler batches $\mathrm{A}$ and $\mathrm{B}$ (a), between budesonide/formoterol Easyhaler and Symbicort Turbuhaler batch A (b), and between budesonide/formoterol Easyhaler and Symbicort Turbuhaler batch B (c) in the fourth study (PP population). The bioequivalence limits are shown with dotted lines.

the development programs of the most recently approved products have employed PK studies rather than imaging studies when comparing lung dose between an originator and a second entry product. ${ }^{(24,25,29)}$

The objective of developing an IVIVC in general is to establish a predictive mathematical model describing the
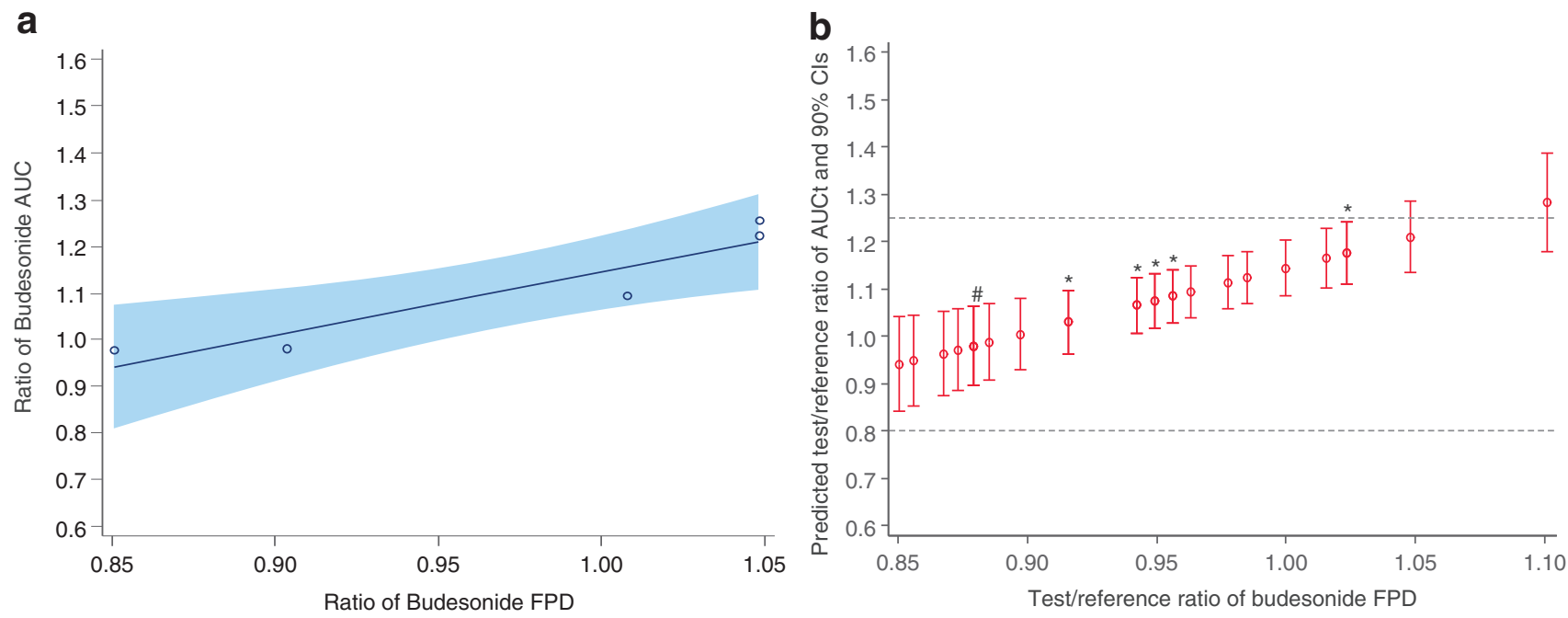

FIG. 6. IVIVC model for budesonide $\mathrm{AUC}_{\mathrm{t}}(\mathbf{a})$, and prediction of $\mathrm{T} / \mathrm{R}$-ratio of budesonide $\mathrm{AUC}_{\mathrm{t}}$ with different FPD ratios (T/R-ratio estimates and 90\% CIs, 26 different reference batches, $* 2$ batches, \#3 batches) (b). 


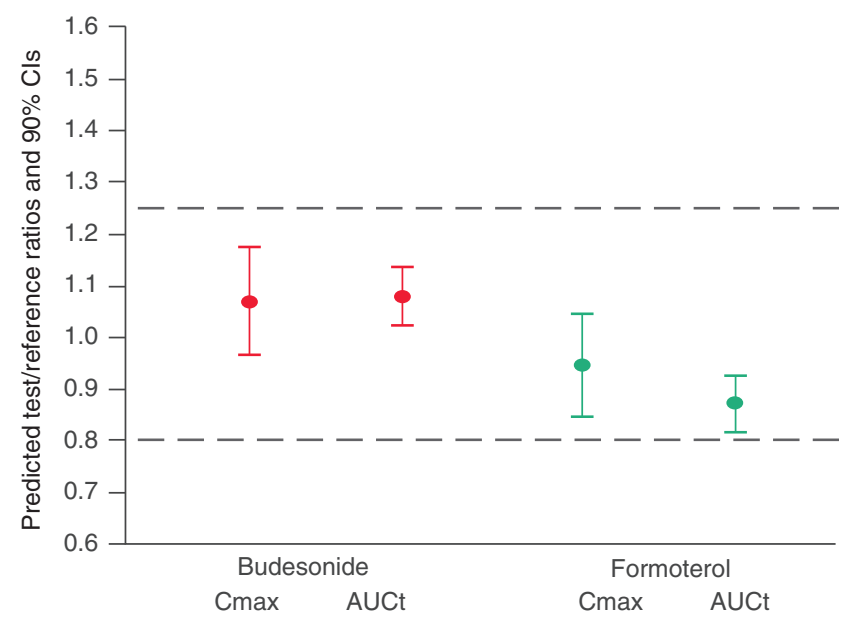

FIG. 7. Predicted study outcome for budesonide/formoterol Easyhaler and the median FPD reference product batch comparison (estimated T/R ratios and $90 \%$ CIs).

evidence of the FPD being a good predictor for lung bioavailability. ${ }^{(32,33)}$ The current regulatory guidance for IVIVC is only applicable to oral dosage forms. ${ }^{(22,23)}$ Even though the PK studies conducted were similar in the respect of the study design and study subjects the limitation of the IVIVC is that the studies were not planned for IVIVC development purposes but models were constructed retrospectively. The other limitation of the models is the lack of different test product batches. However, the Easyhaler batch studied was found to be representative among the manufactured production scale batches.

The practical challenges in performing PK studies with OIPs are many. A number of details need to be standardized but nevertheless mistakes can occur. The correct inhalation technique for the devices may differ resulting in inhalation bias. Therefore, the inhalation technique for both devices was taught and practiced beforehand. The aim was to minimize variability caused by subject-related factors, of which inhalation technique was considered to be the most critical. The manufacturers' instructions were used. The subjects adopted the techniques well and the variability of the PK parameters was of similar magnitude as in a previous study with Turbuhaler in healthy volunteers. ${ }^{(34)}$ In a double-blind trial study, personnel remains objective and if unsuccessful administration occurred the study period could be discontinued before blood sampling and repeat visit organized. Re-scheduling periods was limited to maximum of two per subject in our studies. However, only eight periods in total were re-scheduled (approximately 1\%). Intense blood sampling was also well managed by the experienced study personnel. For drug substances with early $t_{\max }$ like formoterol frequent sampling shortly, a few minutes, after dosing is essential.

During the development, the reference product was extensively studied in vitro to obtain a solid understanding of reference product characteristics. The results of the reference product FPD analysis ( 28 batches) confirmed that there is batch to batch variability in the FPDs. This is typical for the dosage form in question and understandable in the light of in vitro specifications of approved OIPs which allow FPD variance of $\pm 20 \%$ to $\pm 45 \%$ of the mean. ${ }^{(35)}$ The overall number of studied reference product batches can be considered high, bearing in mind that the availability of different batches on the market at certain time is limited. Due to a limited availability, procurement may need to be spread over fairly long period, as in our case over approximately a year and a half. Therefore, it is believed that the gathered database is a good illustration of the in vitro performance of the reference product and a strong basis for a reliable batch to batch comparison. Naturally the FPD result level may be a subject to the measurement set-up specific to the laboratory in question unless the exact methods have been established and validated elsewhere. However, regardless of the result level the use of the same set-up reveals the differences between the batches. All FPD analyses were carried out by the same external laboratory.

In the fourth study the test product's performance in relation to close to median FPD reference batch and an extreme FPD batch (high) was demonstrated. Lung dose after Easyhaler was bioequivalent with the former but not with the latter. Based on the study results, it also appears evident that two reference product batches on the market with different FPDs might not be bioequivalent when tested in a sensitive PK study setting. However, the results have to be considered also against the extensive published clinical data with the reference product for the treatment of asthma and COPD. ${ }^{(8-11)}$

Even though BE was not shown for lung deposition between the batches, there are no data available showing that efficacy or safety of the product is compromised from batch to batch (within the approved specification limits). This would suggest the high discriminative nature of PK studies over clinical studies. Studies by Daley-Yates and co-workers support this conclusion as they reported that differences displayed in PK studies between two salmeterol/fluticasone combination products (DPIs) could not be shown in a studies with pharmacodynamics end points. ${ }^{(36,37)}$ However, the studies might have had a limited sensitivity to show differences between the formulations as only one dose level was included. On the other hand, in a study where salmeterol chlorofuorocarbon (CFC) and non-CFC propellant MDIs were compared on 50,150, and $300 \mu \mathrm{g}$ doses the PK and pharmacodynamic result were in agreement. ${ }^{(38)}$ The higher systemic exposure, based on $\mathrm{AUC}_{\mathrm{t}}$ and $\mathrm{C}_{\max }$, following administration of $\mathrm{CFC}$ formulation, led to significantly greater systemic pharmacodynamic effects.

For budesonide/formoterol Easyhaler, the same batch was used in all four studies and it could be argued that the results are influenced by changes over time in the test batch rather than by different reference batches. That, however, was not the case. The time between the administration of the first and the last dose in the PK studies was approximately 14 months. During that time the test batch was analyzed four times and its FPD levels remained stable. This is in accordance what we have seen for both budesonide/formoterol Easyhaler and Symbicort Turbuhaler. FPDs do not change remarkably along the aging of the product batch.

The selection of the reference product batch to be used in the BE study is the responsibility of the sponsor and it is advisable to investigate several batches when selecting a reference product batch for the study. ${ }^{(39)}$ However, there are no criteria available for a representative reference batch. The number of batches studied before the first two studies 
was 6 , before the last two studies 24 , and by the end of the budesonide/formoterol Easyhaler registration process FPD results of altogether 28 reference batches were available. Obviously the choice of the reference batch for the first studies was not completely successful, as the FPDs of that batch were later found to be somewhat low. The studies conducted clearly show that the reference batch selection is crucial and can have a major impact on the results.

\section{Conclusions}

Equivalence regarding both safety and efficacy between two OIPs, budesonide/formoterol Easyhaler and Symbicort Turbuhaler was shown based on totality of evidence from four PK studies and IVIVC analyses, and therefore, therapeutic equivalence between the products can be concluded. The results of the PK studies are likely dependent on the variability of FPDs of the reference product batches.

\section{Acknowledgments}

Orion Pharma funded these studies. We are grateful to Anita Happonen for supplying the investigational medicinal products, Leena Mattila for the conduct of the pivotal studies (principal investigator), Britt-Marie Lindström and Rajesh Joshi for the statistical analysis, and Shrestha Roy, Ulof Selroos, and Sanna Valkonen for medical writing support.

\section{Author Disclosure Statement}

SL, US, JH, JK, MV, and MK are employees of Orion Pharma. RF is an employee of PAREXEL International GmbH.

\section{References}

1. From the Global Strategy for Asthma Management and Prevention, Global Initiative for Asthma (GINA) 2014. Available from: http://www.ginasthma.org/. Last access: 2/23/15.

2. From the Global Strategy for the Diagnosis, Management, and Prevention of COPD, Global Initiative for Chronic Obstructive Lung Disease (GOLD) 2015. Available from: http://www.goldcopd.org/. Last access: 2/23/15.

3. Haahtela T, Järvinen M, Kava T, Kiviranta K, Koskinen S, Lehtonen K, Nikander K, Persson T, Reinikainen K, Selroos O, Sovijärvi A, Stenius-Aarniala B, Svahn T, Tammivaara $\mathrm{R}$, and Laitinen L: Comparison of a $\beta_{2}$-agonist, terbutaline, with an inhaled corticosteroid, budesonide, in newly detected asthma. N Engl J Med. 1991;325:388-392.

4. Haahtela T, Järvinen M, Kava T, Kiviranta K, Koskinen S, Lehtonen K, Nikander K, Persson T, Selroos O, Sovijärvi A, Stenius-Aarniala B, Svahn T, Tammivaara R, and Laitinen L: Effects of reducing or discontinuing inhaled budesonide in patients with mild asthma. $\mathrm{N}$ Engl $\mathrm{J}$ Med. 1994;331:700-705.

5. Barnes PJ: Scientific rationale for inhaled combination therapy with long-acting $\beta_{2}$-agonists and corticosteroids. Eur Respir J. 2002;19:182-191.

6. Marceau C, Lemière C, Berbiche D, Perreault S, and Blais L: Persistence, adherence, and effectiveness of combination therapy among adult patients with asthma. J Allergy Clin Immunol. 2006;118:574-581.

7. Murphy KR, and Bender BG: Treatment of moderate to severe asthma: Patient perspectives on combination inhaler therapy and implications for adherence. J Asthma Allergy. 2009;2:63-72.

8. Goldsmith DR, and Keating GM: Budesonide/formoterol. A review of its use in asthma. Drugs. 2004;64:1597-1618.

9. Hodgson D, Mortimer K, and Harrison T: Budesonide/ formoterol in the treatment of asthma. Expert Rev Respir Med. 2010;4:557-566.

10. Edwards SJ, von Maltzahn R, Naya IP, and Harrison T: Budesonide/formoterol for maintenance and reliever therapy of asthma: A meta analysis of randomised controlled trials. Int J Clin Pract. 2010;64:619-627.

11. Peters M: Single-inhaler combination therapy for maintenance and relief of asthma: A new strategy in disease management. Drugs. 2009;69:137-150.

12. Sears MR, and Radner F: Safety of budesonide/formoterol maintenance and reliever therapy in asthma trials. Respir Med. 2009;103:1960-1968.

13. Calverley PM, Boonsawat W, Cseke Z, Zhong N, Peterson $\mathrm{S}$, and Olsson $\mathrm{H}$ : Maintenance therapy with budesonide and formoterol in chronic obstructive pulmonary disease. Eur Respir J. 2003;22:912-919.

14. Szafranski W, Cukier A, Ramirez A, Menga G, Sansores R, Nahabedian S, Peterson S, and Olsson H: Efficacy and safety of budesonide/formoterol in the management of obstructive pulmonary disease. Eur Respir J. 2003;21:74-81.

15. Reynolds NA, Perry CM, and Keating GM: Budesonide/ formoterol in chronic obstructive pulmonary disease. Drugs. 2004; 64:431-441.

16. Scott LJ: Budesonide/formoterol Turbuhaler. Drugs. 2012; 72:395-414.

17. van der Palen J, Klein JJ, van Herwaarden CL, Zielhuis GA, and Seydel ER: Multiple inhalers confuse asthma patients. Eur Respir J. 1999;14:1034-1037.

18. CHMP (2009). Guideline on the requirements for clinical documentation for orally inhaled products (OIP) including the requirements for demonstration of therapeutic equivalence between two inhaled products for use in the treatment of Asthma and Chronic Obstructive Pulmonary Disease (COPD). Available at: http://www.ema.europa.eu/docs/en_GB/ document_library/Scientific_guideline/2009/09/WC500003504 .pdf. Last access: 2/23/15.

19. European Pharmacopoeia monograph Preparations for Inhalation: Aerodynamic assessment of fine particles. Available at: http://lib.njutcm.edu.cn/yaodian/ep/EP501E/ 02_methods_of_analysis/2.9._pharmaceutical_technical_ procedures/2.9.18.\%20Preparations\%20for\%20inhalation $\% 20$ $\% 20$ aerodynamic $\% 20$ assessment $\% 20$ of $\% 20$ fine $\% 20$ particles/ 2.9.18.pdf. Last access: 2/23/15.

20. Coaty J, Pierce A, and Swanson J: Analytical method for the determination of budesonide in human $\mathrm{K}_{3}$ EDTA plasma by LC/MS/MS. PPD Method P429.01, May 2010.

21. Wilking M, Zhang ZP, and Zheng N: Analytical method for the determination of formoterol in human lithium heparin plasma by LC/MS/MS. PPD Method P860.02, July 2008.

22. CPMP (1999). Note for guidance on quality of modified release products CPMP/QWP/604/96. Available at: http:// www.ema.europa.eu/docs/en_GB/document_library/Scientific_ guideline/2009/09/WC500003664.pdf. Last access: 2/23/15.

23. US Food and Drug Administration: Guidance for IndustryExtended Release Oral Dosage Forms: Development, Evaluation, and Application of In Vitro/In Vivo Correlations. 1997.

24. Public assessment report for Bufomix Easyhaler. 2014. Available at: https://docetp.mpa.se/LMF/Bufomix\%20Easy 
haler\%20inhalation\%20powder\%20ENG\%20PAR.pdf. Last access: 2/23/15.

25. European public assessment report (EPAR) for DuoResp Spiromax. 2014. Available at: http://www.ema.europa.eu/docs/ en_GB/document_library/EPAR_-_Public_assessment_report/ human/002348/WC500167183.pdf. Last access: 2/23/15.

26. Malmberg LP, Everard ML, Haikarainen J, and Lähelmä S: Evaluation of in vitro and in vivo flow rate dependency of budesonide/formoterol Easyhaler ${ }^{\circledR}$.J Aerosol Med Pulm Drug Deliv. 2014;27:329-340.

27. Scheuch G, Bennett W, Borgström L, Clark A, Dalby R, Dolovich M, Fleming J, Gehr P, Gonda I, O’Callaghan C, Taylor G, and Newman S: Deposition, imaging, and clearance: What remains to be done? J Aerosol Med Pulm Drug Deliv. 2010;23:S39-57.

28. García-Arieta A: A European perspective on orally inhaled products: In vitro requirements for a biowaiver. J Aerosol Med Pulm Drug Deliv. 2014;27:419-429.

29. Public assessment report for Airflusal Forspiro. 2014. Available at: https://docetp.mpa.se/LMF/Airflusal\%20Forspiro,\% 20inhalation \%20powder,\%20pre-dispensed \%20ENG\%20 PAR.pdf. Last access: 2/23/15.

30. Silkstone VL, Dennis JH, Pieron CA, and Chrystyn H: An investigation of in vitro/in vivo correlations for salbutamol nebulized by eight systems. J Aerosol Med. 2002;15:251-259.

31. Newman SP, and Chan HK: In vitro/in vivo comparisons in pulmonary drug delivery. J Aerosol Med Pulm Drug Deliv. 2008;21:77-84.

32. Richardson $\mathrm{CH}$, de Matas $\mathrm{M}$, Hosker $\mathrm{H}$, Mukherjee R, Wong I, and Chrystyn H: Determination of the relative bioavailability of salbutamol to the lungs following inhalation from dry powder inhaler formulations containing drug substance manufactured by supercritical fluids and micronization. Pharm Res. 2007;24:2008-2017.

33. Srichana T, Suedee R, Muanpanarai D, and Tanmanee N: The study of in vitro-in vivo correlation: Pharmacokinetics and pharmacodynamics of albuterol dry powder inhalers. J Pharm Sci. 2005;94:220-230.

34. Dalby C, Polanowski T, Larsson T, Borgström L, Edsbäcker S, and Harrisson TW: The bioavailability and airway clearance of the steroid component of budesonide/ formoterol and salmeterol/fluticasone after inhaled administration in patients with COPD and healthy subjects: A randomized controlled trial. Respir Res 2009;10:1-11.

35. Evans C, Cipolla D, Chesworth T, Agurell E, Ahrens R, Conner D, Dissanayake S, Dolovich M, Doub W, Fuglsang A, García Arieta A, Golden M, Hermann R, Hochhaus G, Holmes S, Lafferty P, Lyapustina S, Nair P, O'Connor D,
Parkins D, Peterson I, Reisner C, Sandell D, Singh GJ, Weda M, and Watson P: Equivalence considerations for orally inhaled products for local action-ISAM/IPAC-RS European Workshop report. J Aerosol Med Pulm Drug Deliv. 2012;25:117-139.

36. Daley-Yates PT, Mehta R, Chan RH, Despa SX, and Louey MD: Pharmacokinetics and pharmacodynamics of fluticasone propionate and salmeterol delivered as a combination dry powder from a capsule-based inhaler and a multidose inhaler in asthma and COPD patients. J Aerosol Med Pulm Drug Deliv. 2014;27:279-289.

37. Daley-Yates PT, Parkins DA, Thomas MJ, Gillett B, House $\mathrm{KW}$, and Ortega HG: Pharmacokinetic, pharmacodynamic, efficacy, and safety data from two randomized, doubleblind studies in patients with asthma and an in vitro study comparing two dry-powder inhalers delivering a combination of salmeterol 50 microg and fluticasone propionate 250 microg: Implications for establishing bioequivalence of inhaled products. Clin Ther. 2009;31:370-385.

38. Kempsford R, Handel M, Mehta R, De Silva M, and Daley-Yates P: Comparison of the systemic pharmacodynamic effects and pharmacokinetics of salmeterol delivered by CFC propellant and non-CFC propellant metered dose inhalers in healthy subjects. Respir Med. 2005;99: S11-19.

39. CPMP (2010). Guideline on the investigation of bioequivalence CPMP/EWP/QWP/1401/98 Rev. 1/Corr**. Available at: http://www.ema.europa.eu/docs/en_GB/document_library/ Scientific_guideline/2010/01/WC500070039.pdf. Last access: $2 / 23 / 15$.

Received on November 4, 2014 in final form, February 2, 2015

Reviewed by: Hartmut Derendorf Gur Jai Pal Singh

Address correspondence to: Satu Lähelmä, MSc Orion Corporation ORION PHARMA Volttikatu 8, PL 1780 FI-70701 Kuopio Finland

E-mail: satu.lahelma@orionpharma.com 